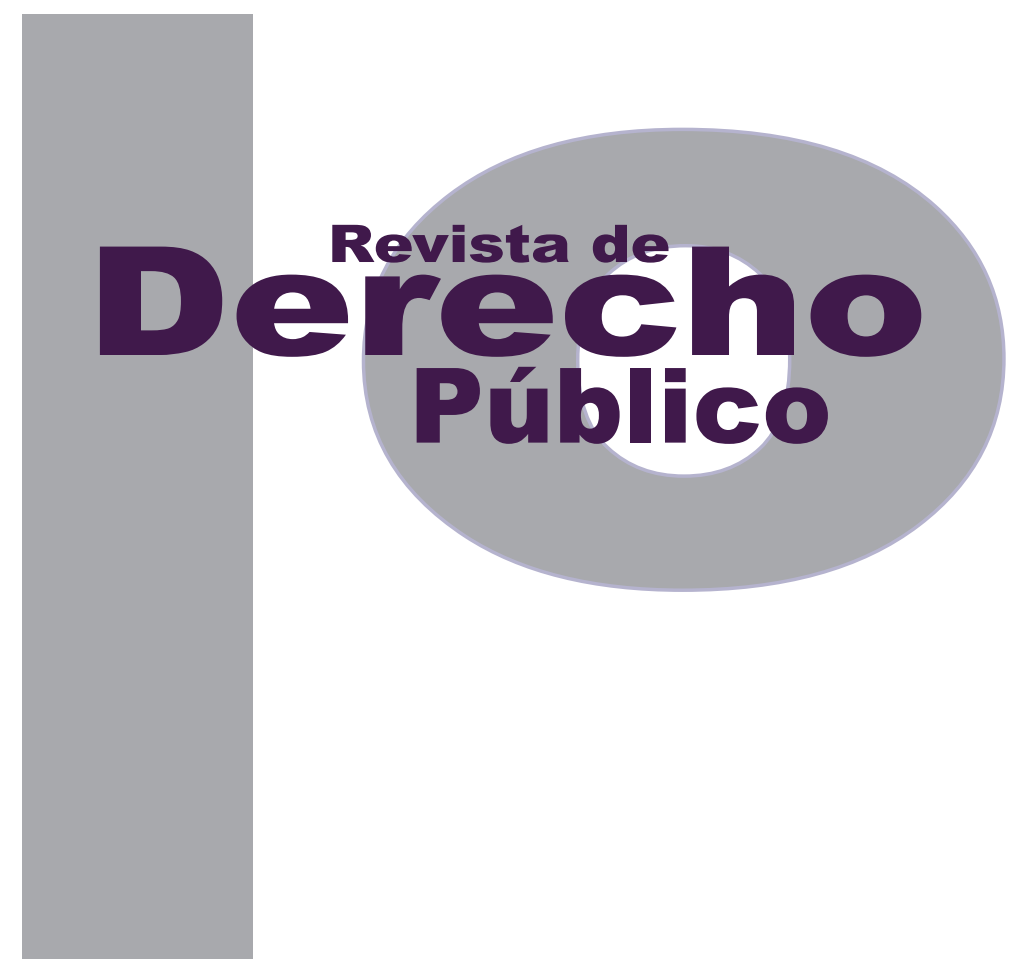

LAS COMUNIDADES ORGANIZADAS COMO PRESTADORAS DEL SERVICIO PÚBLICO DE ACUEDUCTO EN LA ZONA RURAL DE BOGOTÁ D. C.: EL CASO DE LOS ACUEDUCTOS VEREDALES DE Mochuelo BAJO, PASQUilla, LA UNIÓN y ANDES

\author{
Antonio Alejandro Barreto Moreno \\ Artículo de reflexión \\ DOI: http://dx.doi.org/10.15425/redepub.33.2014.27 \\ Universidad de los Andes \\ Facultad de Derecho \\ Revista de Derecho Público N. ${ }^{\circ} 33$
}

Julio - Diciembre de 2014. ISSN 1909-7778 
Las comunidades organizadas como prestadoras del servicio público de acueducto en la zona rural de Bogotá D. C.: el caso de los acueductos veredales de Mochuelo Bajo, Pasquilla, la Unión y Andes

\section{Resumen}

El presente escrito valida el régimen de prestación del servicio público de acueducto en las zonas rurales, concretamente en la zona rural de Bogotá, en cabeza de las comunidades autorizadas. Señala el deber del Estado, a través del municipio, de garantizar la prestación eficiente de los servicios públicos domiciliarios en todo su territorio, incluida la zona rural. No obstante, las cargas administrativas impuestas por la ley y las autoridades de control, las dificultades técnicas, la informalidad, el abandono estatal y en general un sinnúmero de limitaciones, impiden que la gestión de dicho servicio en esa zona sea continua, permanente, ininterrumpida, con amplia cobertura y de calidad.

Palabras clave: derecho administrativo, servicio público domiciliario, servicio de acueducto, derecho de aguas y ruralidad.

Organized communities as aqueduct public service providers in rural areas of Bogotá D.C.: The case of the village aqueducts of Mochuelo, Bajo, Pasquilla, La Unión and Andes

\section{Abstract}

The document analyzes the regulation applicable to the water services in rural areas, with special emphasis in those provided through authorized communities in Bogotá's rural areas. The document highlights the State's duty to guarantee the provision of water services through municipalities; and how such provision is affected by several factors, including regulatory burdens established by law and governmental agencies, technical difficulties, informality, and lack of government presence. All these limiting factors prevent a continuous and permanent management of water services, with the view of providing high quality broad coverage.

Keywords: derecho administrativo, servicio público domiciliario, servicio de acueducto, derecho de aguas y ruralidad.

As comunidades organizadas como prestadoras de serviço público de aqueduto na zona rural de Bogotá D.C.: o caso dos aquedutos das veredas de Mochuelo Bajo, Pasquilla, a Unión e Andes

\section{Resumo}

O presente escrito valida o regime de prestação de serviço público de aqueduto nas zonas rurais, concretamente na zona rural de Bogotá através das comunidades autorizadas. Mostra o dever do Estado, por meio do município, de garantir a prestação eficiente dos serviços públicos domiciliários em todo seu território, incluindo a zona rural. Não obstante, as cargas administrativas impostas pela lei e pelas autoridades de controle, as dificuldades técnicas, a informalidade, o abandono estatal e em geral, diversas limitações, impedem que a gestão de dito serviço nessa zona seja contínua, permanente, ininterrupta, com ampla cobertura e de qualidade.

Palavras-chave: direito administrativo, serviço público domiciliário, serviço de aqueduto, direito de águas e ruralidade. 


\title{
Las comunidades organizadas como prestadoras del servicio público de acueducto en la zona rural de Bogotá D. C.: el caso de los acueductos veredales de Mochuelo Bajo, Pasquilla, la Unión y Andes*
}

\author{
Antonio Alejandro Barreto Moreno**
}

\section{SUMARIO}

Introducción - I. EL SERVICIO PÚBLICO DE ACUEDUCTO A NIVEL RURAL - A. El municipio como mecanismo asignado del Estado para la prestación del servicio público domiciliario - B. Los prestadores de servicios públicos particulares y el caso rural - II. LA PRESTACIÓN DEL SERVICIO PÚBLICO DOMICILIARIO DE ACUEDUCTO EN LA ZONA RURAL DE LA CIUDAD DE BOGOTÁ - A. La ruralidad en la ciudad de Bogotá - 1. El perímetro urbano de la ciudad de Bogotá - 1.1. Ubicación y características fundamentales de la ruralidad - 1.2. Política del agua en la zona rural - 1.3. Los acueductos veredales en Bogotá - B. La experiencia del servicio de acueducto veredal - III. CONCLUSIONES - Referencias.

* Cómo citar este artículo: Barreto Moreno, A. A. (Diciembre, 2014). Las comunidades organizadas como prestadoras del servicio público de acueducto en la zona rural de Bogotá D. C.: el caso de los acueductos veredales de Mochuelo Bajo, Pasquilla, La Unión y Andes. Revista de Derecho Público, 33. Universidad de los Andes (Colombia).

La investigación en terreno para la elaboración de este escrito se hizo en el primer trimestre del año 2010, el texto se terminó de escribir a finales del mismo año, y hace parte de la investigación amplia sobre el servicio público domiciliario de acueducto, realizada en el marco de la tesis doctoral del autor.

** Abogado de la Universidad Colegio Mayor de Nuestra Señora del Rosario; especialista en Derecho de Daños de la Universidad de Salamanca, España; magíster en Derecho de la Universidad de los Andes y doctor en Derecho de la misma institución educativa; pasante doctoral de la Universidad de Nantes, Francia, y miembro del grupo de investigación de Derecho Público de la Universidad de los Andes. Profesor de cátedra de la Universidad de los Andes. 
Introducción

Dos características ampliamente difundidas por la Administración Distrital de Bogotá sobre la prestación del servicio público de acueducto en la ciudad son: cobertura total y calidad del agua.

En este sentido, se divulga con frecuencia y se repite vía prensa que la cobertura de acueducto es del $99.69 \%$ y que "el agua distribuida por el Acueducto de Bogotá en el año 2009, es potable, apta para el consumo humano y cumple con las disposiciones legales establecidas por el Gobierno Nacional" (Empresa de Acueducto y Alcantarillado de Bogotá [EAAB-ESP], 2010), lo que sin duda es un alivio para los usuarios de este recurso. ${ }^{1}$

Sin embargo, no se tiene presente o se omite una precisión: que esa información se limita al perímetro urbano de la ciudad, ${ }^{2}$ es decir aquel en que la EAAB-ESP tiene su cobertura, con lo

1 La Organización Mundial de la Salud y Naciones Unidas han propendido por retirar cualquier contenido económico y reconocer el carácter de derecho humano del acceso al agua: "En muchas partes del mundo, como Europa o Norteamérica, la gente da por sentado que basta con abrir un grifo para tener agua limpia y segura para beber, cocinar o lavar. Sin embargo, más de mil millones de seres humanos se ven obligados a recurrir a fuentes de abastecimiento de agua potencialmente nocivas.

... La Asamblea General de las Naciones Unidas ha proclamado el periodo de 2005 a 2015 Decenio Internacional para la Acción "El agua, fuente de vida", que dará comienzo el 22 de marzo de 2005, Día Mundial del Agua. Este Decenio contribuirá a que los objetivos mundiales se centren con más ímpetu en los asuntos relacionados con el agua, al tiempo que se trata de asegurar la participación de la mujer en los programas de desarrollo relativos al agua y se promueve la cooperación en todos los ámbitos" (oмs, 2014).

2 Respuesta a derecho de petición Empresa de Acueducto y Alcantarillado de Bogotá ESP, oficio 30200-S-2010-157024, marzo 26 de 2010. cual se excluye toda la parte rural del Distrito Capital. $^{3}$

La ausencia de operación y prestación del servicio en el sector rural por parte de la EAAB-ESP se explicaría por múltiples razones, ${ }^{4}$ de las cuales podríamos mencionar algunas básicas: (i) porque así lo señala el plan de ordenamiento territorial que limita su jurisdicción al área urbana, probablemente con el propósito de evitar procesos de conurbación, y (ii) porque se trata de una empresa industrial y comercial del distrito, es decir, que su objeto social está dirigido a la obtención de lucro y evidentemente el mercado rural no resulta atractivo con ese propósito.

Esto no significa que las zonas rurales deban carecer de los servicios públicos domiciliarios de acueducto y alcantarillado, o que no esté regulado su suministro, todo lo contrario, la Constitución y la ley desarrollan este ámbito dentro del deber estatal de garantizar a todos los ciudadanos, sin distinciones, la prestación de esos servicios. No obstante, todo indica que la gestión de estos en el área rural de Bogotá D.C. carece de condiciones administrativas y técnicas que permitan su prestación de manera continua, con amplia cobertura y de calidad.

3 Para información general y básica, Bogotá D. C. tiene una zona rural de 122.256 hectáreas, que comparada con la total de 160.686.26 hectáreas, indica que aproximadamente el $75 \%$ del territorio total de la ciudad es rural (Secretaría de Planeación Distrital en respuesta derecho de petición 1-2010-12323 abril 26 de 2010).

4 Quizá la política pública de liberalización y privatización sea una de las razones estructurales cuya fuente es la Ley 142 de 1994. Ver artículo del autor: "La estructura regulativa del servicio público domiciliario de aguas en el caso de la venta de agua en bloque, más allá del enfoque mercantil", que está próximo a publicar la Universidad de los Andes en un texto de varios escritos sobre regulación, con la coordinación del profesor Everaldo Lamprea M. 
En este sentido, es claro de tiempo atrás lo que ocurre con la prestación del servicio de acueducto en la zona urbana de la ciudad de Bogotá, pero no ocurre lo mismo con la zona rural. ${ }^{5}$

El presente escrito se preocupará por validar el régimen de prestación del servicio público de acueducto en la zona rural. Inicialmente se expondrá en cabeza de quién está la prestación y en un segundo momento se hará referencia a los prestadores reconocidos por la legislación colombiana. Adicionalmente y con el fin de no dejar este ejercicio solo en exposiciones teóricas, se hará alusión a la situación de algunas pequeñas áreas rurales de la ciudad de Bogotá, mediante el estudio cualitativo de tres experiencias de servicio, ${ }^{6}$ a saber: Ios acueductos veredales de Mochuelo Bajo, Pasquilla, la Unión y Andes, los cuales son operados en su orden por la Asociación de Usuarios de Aguas Calientes, Asociación Pasquilla Centro y Asopicos de Bocagrande E.S.P. (La Unión y Andes).

Este corto ejercicio empírico sin duda no nos llevará a presentar conclusiones definitivas sobre el servicio de acueducto en la zona rural de la capital, pero sí nos dará elementos para describir en lo básico el funcionamiento del sistema de suministro a este nivel.

$5 \quad$ El análisis empírico de los acueductos veredales que se desarrolla en este trabajo fue adelantado durante el mes de abril de 2010.

6 Hubiera querido ampliar este ejercicio de terreno a más veredas de la ciudad, sin embargo por razones de logística fue imposible dicho cometido. Sin embargo, estas experiencias quizá nos puedan dar una idea general de lo que ocurre en otras zonas rurales, por lo menos de la ciudad de Bogotá.
Este escrito no pretende desvirtuar los avances que en infraestructura y calidad se dan en el nivel urbano, tampoco busca hacer una apología para que se extienda la cobertura y competencia urbana a lo rural, por el contrario, es de gran importancia que lo rural no pierda su sentido. Más bien se trata de dirigir la mirada a una zona por momentos desconocida y abandonada por la acción estatal.

Evidenciar la omisión de los datos del servicio de acueducto en una amplia, por no decir la mayor área (75\%) -territorialmente hablando-de la ciudad de Bogotá es apenas un despertar a varios problemas que se irán desarrollando en este documento.

Por ahora, a este aparte introductorio, agréguese que el servicio de acueducto en la zona rural de Bogotá se suple por la forma característica de las zonas campesinas del país, es decir, por autosuministro directo de las fuentes o bien a través de comunidades organizadas en torno a acueductos veredales. $^{7}$ En todo caso, el sumi-

7 Denominaré "acueductos veredales" a aquellas infraestructuras de acueducto construidas por el Estado (Distrito de Bogotá), entregadas a comunidades organizadas para su administración. Por "organizaciones autorizadas" o "comunidades organizadas" se tendrán las reconocidas por la ley sobre servicios públicos domiciliarios y en general aquellas agrupaciones que prestan el servicio público de acueducto en la zona rural de la ciudad de Bogotá, algunas de ellas inclusive bajo el atuendo de empresas prestadoras de servicios públicos domiciliarios (ESPD). La Superintendencia de Servicios Públicos Domiciliarios (SSPD) en respuesta a un derecho de información señaló: "Ahora bien, de acuerdo con el artículo 15 de la Ley 142 de 1994, pueden prestar servicios públicos domiciliarios, entre otros, las organizaciones autorizadas conforme a esta ley, dentro de las que se cuentan los acueductos veredales a los que hace referencia su comunicación. Por lo tanto los acueductos veredales están regidos por la Ley 142 de 1994, sus normas reglamentarias, la regulación expedida por la Comisión de Regulación de Agua Potable y Saneamiento Básico y los reglamentos técnicos expedidos por el Ministerio de Medio Ambiente, Vivienda y Desarrollo Territorial". Radicado 20104600140771 del 2 de marzo de 2010. 
nistro a este nivel presenta grandes dificultades de orden administrativo y técnico.

Con este panorama y con el soporte de información suministrada por la administración nacional, ${ }^{8}$ distrital $^{9}$ y la proveniente del trabajo de campo, ${ }^{10}$ la parte de análisis de caso buscará responder la siguiente inquietud: ¿cuál ha sido la experiencia que han tenido las comunidades organizadas con la prestación del servicio de agua potable, dirigida a dos aspectos, la parte administrativa y el funcionamiento del servicio de acueducto que comprende cobertura y calidad del agua? y si esa experiencia permite evidenciar si el Distrito Capital, en efecto, cumple con el deber constitucional de garantizar la prestación del servicio público domiciliario de acueducto en la zona rural de su zona de cobertura.

El presente escrito se dividirá así: en primer lugar y a manera de contextualización teórica, se hace una descripción general de la normativa vigente sobre la prestación del servicio público de acueducto y los operadores autorizados legalmente, haciendo énfasis en el nivel rural (I); la segunda parte, que refleja el trabajo de campo, ${ }^{11}$ presentará el estado actual de la pres-

8 Para los fines de este estudio se solicitó información a través de derechos de petición a la Superintendencia de Servicios Públicos Domiciliarios (SSPD), la Corporación Autónoma Regional (CAR) y la Comisión de Agua Potable y Saneamiento Básico (CRA).

9 Concretamente, la Secretaría de Gobierno de Bogotá y la EAAB-ESP. De la primera no se obtuvo ninguna respuesta.

10 Entrevista a los administradores de los acueductos veredales, así como a sus usuarios y otros actores de la prestación del servicio.

11 Esta parte de la investigación estará soportada mayormente en las visitas a los acueductos veredales y a la comunidad que se sirve de tación del servicio público domiciliario de acueducto en algunas pequeñas áreas rurales de la ciudad de Bogotá D. C. y la experiencia del servicio de acueducto veredal. Este aparte empírico se fundamenta en las visitas que el autor tuvo oportunidad de hacer a los acueductos veredales, y entrevistas con los administradores, plomeros y usuarios de estos prestadores (II).

\section{EL SERVICIO PÚBLICO DE ACUEDUCTO A NIVEL RURAL}

Este aparte tiene como finalidad ubicar al lector en el régimen vigente de los servicios públicos domiciliarios y particularmente en el de acueducto. Se desarrollará de la siguiente forma: inicialmente se tratará lo relativo a la garantía de la prestación del servicio público domiciliario en cabeza del Estado y su mecanismo ejecutorio constitucional: el municipio (A); luego se verá lo relativo a los prestadores de servicios públicos domiciliarios de carácter particular, con hincapié en aquellos que lo prestan por lo general en las zonas rurales: las comunidades organizadas autorizadas para prestar el servicio público de acueducto (B).

\section{A. El municipio como mecanismo asignado del Estado para la prestación del servicio público domiciliario}

La Constitución Política de Colombia menciona que como consecuencia de su compromiso so-

ellos, y a las entrevistas realizadas a los actores de la prestación a este nivel. 
cial ${ }^{12}$ es deber del Estado "garantizar" la prestación de los servicios públicos (art. 311 y 365), bien por sí mismo de forma directa a través de municipios, departamentos o entidades descentralizadas (art. 367) o indirectamente por medio de particulares (art. 365 párr. 2), llámense comunidades organizadas, empresas prestadoras de servicios públicos domiciliarios y con mayor precisión y de forma exclusiva las autorizadas por el artículo 15 de la Ley 142 de 1994.

Esto muestra que en la actualidad no existe, como en épocas pasadas, ${ }^{13}$ monopolio en cabeza del Estado en la prestación de los servicios públicos, pero ello no significa que esta quede exclusivamente a expensas de terceros particulares.

En aquellos casos en los cuales no sea posible la prestación del servicio por los autorizados por la ley, tendrá el Estado que suplir dicha falencia por intermedio de su estructura y primeramente por los municipios, quienes son los llamados a "solucionar las necesidades insatisfechas de salud, educación, saneamiento ambiental, agua potable, servicios públicos domiciliarios" (art. 3 num. 5 Ley 136 de 1994). No obstante, el municipio puede por permisión constitucional acudir a terceros para cumplir el deber de garantía (art. 365).

12 Con esta referencia aludo a toda la construcción doctrinal de Estado social de derecho, que se refleja con gran impacto en la prestación de servicios públicos domiciliarios.

13 Artículo 10 y 11 del Acto Legislativo 1 de 1936 y artículo 6 del Acto Legislativo 1 de 1968 (modificatorio del artículo 32 de la Constitución Nacional)
Sobre este particular se lee en la exposición de motivos del Proyecto de ley "por el cual se establece el régimen de los servicios públicos domiciliarios" lo siguiente: “El municipio es la entidad política y regional alrededor de la cual debe organizarse la prestación de los servicios públicos domiciliarios". Más adelante agrega la motivación,

sin embargo, el proyecto permite que los municipios presten directamente (es decir con sus empleados, patrimonio y personalidad jurídica) los servicios públicos domiciliarios, cuando juzguen que no les conviene que sea una empresa la que realice tal labor, o cuando no haya empresa que quiera adelantarla (art. $5^{\circ}$ ). En las zonas rurales y los municipios menores, la prestación de los servicios de agua potable y saneamiento podrá adelantarse por medio de cooperativas, precooperativas y otras organizaciones comunitarias con personería jurídica (art. 113) (Proyecto de ley n. 197 de 1992, p. 24$) \cdot{ }^{14}$

En este sentido, el Consejo de Estado indicó que: "Debe la Sala comenzar por advertir que no acertó el Tribunal cuando para exonerar a la administración municipal alega que en los corregimientos el servicio es prestado por acueductos veredales, pues la prestación del servicio de acueducto es responsabilidad primerísima de los municipios" (expediente n. ${ }^{\circ}$ 85001-23-31-000-2004-00027-01(AP)). ${ }^{15}$

14 Proyecto de origen gubernamental presentado por los ministros de Hacienda y Crédito Público (Rudolf Hommes), Minas y Energía (Guido Nule), Comunicaciones (William Jaramillo), Obras Públicas y Transporte (Jorge Bendeck) y Desarrollo Económico (Luis Alberto Moreno).

15 En el mismo sentido y con ponencia del mismo consejero, la sentencia de acción popular, expediente n. ${ }^{\circ} 1262$ de 18 de octubre de 2007. 
Sin ir más lejos, el artículo 76 de la Ley 715 de 2001 sobre Sistema General de Participaciones, señaló sobre el particular: "Competencias del municipio en otros sectores... 76.1. Servicios Públicos. Realizar directamente o a través de terceros en materia de servicios públicos además de las competencias establecidas en otras normas vigentes la construcción, ampliación, rehabilitación y mejoramiento de la infraestructura de servicios públicos".

Se tiene entonces que los municipios son los llamados inicialmente a asegurar la prestación del servicio público de acueducto, bien directamente o a través de particulares que cumplan con los requisitos de ley como se verá adelante. Es inaceptable que las autoridades municipales pretendan evadir su competencia con el pretexto de que no exista un tercero particular que quiera asumir la prestación del servicio.

El municipio, por mandato constitucional (art. 311), está llamado a actuar activamente en la prestación de los servicios públicos, solo así se puede garantizar su prestación. Más aún, el municipio no podría excusarse de su responsabilidad si existiendo prestadores del servicio domiciliario, estos no lo ejecutan ajustado a las reglas administrativas y de calidad vigentes.

El deber de garantía para el municipio no se cumple simplemente con verificar la existencia de prestadores en su área de competencia; también incluye velar porque el servicio prestado cumpla con estándares de administración y técnicos (cobertura, prestación continua e ininterrumpida, calidad del agua y satisfacción), de lo contrario deberá acudir o denunciar ante los demás controles estatales existentes (superintendencias, ministerios, corporaciones autónomas regionales, etc.) para que estos tomen las medidas sancionatorias o de intervención que reconoce la ley. ¿Cómo podría entenderse el mandato constitucional si el prestador o el servicio prestado no satisfacen de forma global (técnica- administrativa) la normatividad vigente en la materia y el municipio hace caso omiso de tales irregularidades?

\section{B. Los prestadores de servicios públicos particulares y el caso rural}

Las obligaciones que se han comentado son atribuibles también a la ciudad de Bogotá D. C. en sus zonas urbana y rural.

Como se vio, el municipio no puede dejar al albur la prestación del servicio público y para ello debe asegurarse de que toda su jurisdicción tenga cuantos operadores sean necesarios, de lo contrario deberá entrar a asumirlo directamente. Además, y en virtud de la garantía de prestación que le impone la Constitución, debe verificar que los prestadores en su territorio estén debidamente reconocidos para el efecto y lleven a cabo su labor dentro de los parámetros legales.

Si bien no puede dársele una misión regulatoria a los municipios, tampoco se puede desconocer que dentro de sus competencias administrativas, llamadas de "gestión", tienen el deber de velar porque los prestadores del servicio mantengan niveles eficientes de servicio y calidad. ${ }^{16}$

16 Así lo señala la Ley 142 de 1994 en el artículo 2.1. "Garantizar la calidad del bien objeto del servicio público y su disposición final para 
Como se dijo anteriormente, el ordenamiento en materia de servicios públicos domiciliarios incluyó la posibilidad de que actores particulares tomaran parte en el negocio, justificando dicha inserción en que

Una de las razones por las cuales los colombianos no disponen de servicios domiciliarios en cantidad, radica en que no ha habido competencia en el sector; en la práctica, este ha estado sujeto a monopolios oficiales. No ha existido, en la práctica, libertad de entrada al sector de servicios públicos. Y el monopolio oficial limita la posibilidad de vincular recursos a la prestación de los servicios, pues estos quedan dependientes de las disponibilidades fiscales y, en ese sentido, el monopolio impide la ampliación de la cobertura. El monopolio, al mismo tiempo, carece de incentivos para ser eficiente, y ello ocasiona que los usuarios tengan que pagar tarifas innecesariamente altas, y recibir servicios de calidad pobre. La principal víctima del monopolio oficial ha sido, entonces, el usuario (Proyecto de ley n. ${ }^{\circ} 197$ de 1992, p. 24). [Cursivas añadidas].

Más allá de lo acertadas o no de las palabras citadas, y si se comparte esa justificación de ineficiencia estatal, lo cierto es que el sistema autorizó el ingreso de particulares a lo que de forma imprecisa asimiló a un "mercado", el de servicios públicos domiciliarios y sobre esta premisa se continuará con la exposición.

asegurar el mejoramiento de la calidad de vida de los usuarios" y en el 5.1. "Asegurar que se presten a sus habitantes, de manera eficiente, los servicios domiciliarios de acueducto, alcantarillado, aseo, energía eléctrica, y telefonía pública básica conmutada, por empresas de servicios públicos de carácter oficial, privado o mixto, o directamente por la administración central del respectivo municipio en los casos previstos en el artículo siguiente". Nótese la fortaleza de los verbos rectores en ambas disposiciones: "garantizar" y "asegurar".
Como se dijo al comienzo, uno de los intereses básicos de este escrito está en describir la prestación del servicio de acueducto a nivel rural, que como se verá legislativamente, con algunas precisiones jurisdiccionales, no difiere en lo fundamental de lo urbano; entonces lo que se diga de lo rural es la regla en materia de prestación de servicio público domiciliario de acueducto. Así mismo, lo que se diga de la comunidad organizada es igualmente aplicable a las empresas de servicios públicos domiciliarios (E.S.P.). Vale aclarar que no se pretende hacer juicios de vaIor en este aparte, simplemente se trata de describir el modelo existente.

En este orden de ideas, en adelante se estudiarán las denominadas legalmente organizaciones autorizadas "para prestar servicios públicos en municipios menores, zonas rurales y en áreas o zonas urbanas específicas" (L. 142/94 art. 15-4), llamadas genéricamente por la Corte Constitucional "organizaciones solidarias" o "comunidades constituidas" como lo señala la Superintendencia de Servicios Públicos Domiciliarios. ${ }^{17}$ Cualquiera de esos términos hace referencia a una persona jurídica privada sin ánimo de lucro, cuyo objeto es la prestación de servi-

17 "La Honorable Corte Constitucional mediante Sentencia C-741 del 28 de agosto de 2003 con el fin de emplear el término más amplio posible que abarque las personas jurídicas sin ánimo de lucro, emplea el término organizaciones solidarias, término que cobija, entre otras, las fundaciones, asociaciones de beneficio común y las cooperativas, los organismos de segundo y tercer grado que agrupen cooperativas $u$ otras formas asociativas y solidarias de propiedad, las instituciones auxiliares de la Economía Solidaria, las empresas comunitarias, las empresas solidarias de salud, las precooperativas, los fondos de empleados, las asociaciones mutualistas, las empresas de servicios en las formas de administraciones públicas cooperativas, las empresas asociativas de trabajo y todas aquellas formas asociativas solidarias que cumplen con las características mencionadas en el presente capítulo, a que hace referencia el parágrafo $2^{\circ}$ del artículo $6^{\circ} 3$ de la Ley 454 de 1998" (Concepto SSPD-OJ-2004-274). 
cios públicos domiciliarios en cualquier parte del territorio nacional. ${ }^{18}$

Pero, ¿qué distingue a una empresa de servicios públicos domiciliarios de una comunidad organizada? Sobre el particular dice la Corte Constitucional:

Tal como lo reconoce uno de los intervinientes, la medida tiene como finalidad reconocer una situación práctica -la de las organizaciones autorizadas-, "que no en todas las zonas del país habrá interés de los particulares en prestar los servicios públicos porque no existe el mercado suficiente para prestarlos." Así, cuando el mercado no es atractivo, se permite que las "organizaciones autorizadas" presten los servicios que las empresas no están dispuestas a prestar. Es decir, que la medida estaría justificada para que en aquellas zonas donde no es lucrativo la prestación de servicios públicos, puedan participar las "organizaciones autorizadas", pero en donde el mercado resulta atractivo, solo quienes persigan un ánimo de lucro tendrían el privilegio de entrar (sentencia C-741-2003). ${ }^{19}$

Ante la pregunta ¿cuáles son los requisitos que exigen la ley y la Superintendencia para constituirse como comunidad organizada prestadora

18 La Corte Constitucional mediante sentencia C-074-2003 con ponencia del magistrado Manuel José Cepeda, declaró la exequibilidad condicionada del artículo 15-4 de la Ley 142 de 1994 en la medida que se entienda que "tales organizaciones también podrán competir en otras áreas, es decir, en cualquier lugar del territorio nacional". De lo visto en las visitas al sector rural de Bogotá, percibo que las asociaciones apenas con gran esfuerzo tienen capacidad para operar un pequeño acueducto veredal.

19 A primera vista esta precisión contradice y modifica lo dicho por la propia Corte Constitucional en sentencia C-074-2003, en el sentido de aceptar concurrencia entre comunidades organizadas y empresas de servicios públicos en todo el territorio nacional. Quizá el argumento empírico supera el argumento jurídico. de servicios públicos de acueducto y/o alcantarillado?, la SSPD en su respuesta al derecho de petición con radicado 20104600140771 del 2 de marzo de 2010, tras trascribir ampliamente las normas y formatos establecidos por ellos, respondió: “En conclusión, las empresas de servicios públicos, entre ellas las comunidades constituidas y organizadas debidamente, no requieren permiso para desarrollar su objeto social, pero para operar deberán obtener cuando se requiera, las concesiones y permisos de que tratan los artículos 25 y 26 de la Ley 142 de 1994". Luego precisa que

Por lo tanto los acueductos veredales están regidos por la Ley 142 de 1994, sus normas reglamentarias, la regulación expedida por la Comisión de Regulación de Agua Potable y Saneamiento Básico y los reglamentos técnicos expedidos por el Ministerio de Ambiente, Vivienda y Desarrollo Territorial.

En relación con la prestación por parte de organizaciones autorizadas, las reglas están dispuestas en el Decreto 421 de 2000, donde se establecen los requisitos y procedimientos para hacer efectiva la participación de estas comunidades.

Recapitulando, se tiene que las comunidades organizadas deben cumplir con los mismos requisitos de operación de cualquier empresa prestadora de servicios públicos y del propio Estado para la prestación del servicio público de acueducto, sin ninguna discriminación por razón de su capacidad y estructura organizacional. No obstante, de la claridad de la norma y del manejo preciso que de ella hace la Super- 
intendencia, parecería que las asociaciones tienen dificultad para cumplir los requisitos y, por ende, para actuar legalmente.

A manera de ejemplo se hizo la siguiente verificación. Para el caso de Bogotá D. C., en el año 2010 únicamente tres asociaciones contaban con registro ante la SSPD, a saber: Asociación de Usuarios de Aguas Calientes; Asociación de Usuarios Acueducto Aguas Claras Vereda Olarte; y Asociación de Servicios Públicos Comunitarios San Isidro I y II sector San Luis y La Sureña ESP. $^{20}$ Si solo comparamos este dato con los 33 acueductos veredales censados por la EAAB-ESP, que no son todos los de la ciudad, ${ }^{21}$ se observa que no se han inscrito 31 de ellos, pero aun así operan el servicio de acueducto en su zona de influencia.

\section{LA PRESTACIÓN DEL SERVICIO PÚBLICO DOMICILIARIO DE ACUEDUCTO EN LA ZONA RURAL DE LA CIUDAD DE BOGOTÁ D. C.}

Lo anterior nos conecta con la segunda parte del escrito, que da cuenta de la ruralidad en Bogotá y cómo se presta el servicio de acueducto

20 Esta fue la respuesta dada por la SSPD a las preguntas: ¿cuántas y cuáles son las comunidades organizadas prestadoras de servicios públicos de acueducto y/o alcantarillado que están inscritas a la fecha en el registro único de prestadores de servicio R.U.P.S. de esa superintendencia que cumplan con su objeto social en la ciudad de Bogotá D.C., bien sea en la zona rural o urbana?, ¿cuántas de estas comunidades inscritas han dado informe de inicio de actividades?

21 La información de todos los acueductos veredales de la ciudad fue solicitada a la Secretaría de Gobierno de Bogotá, infortunadamente no se pronunció a nuestra petición. Por su parte, la EAAB-ESP aclara que los acueductos veredales a los que se refiere son los que construyó a través de su Unidad Ejecutora Local (UEL). en esta amplia área de la ciudad (A), y la investigación empírica que consistió en visitas a algunos acueductos veredales y entrevistas a varios actores de la prestación, con el fin de hacer una verificación a dos niveles: a las personas que se encargan de la administración y operación del acueducto veredal y a los usuarios de ese servicio (B).

\section{A. La ruralidad en la ciudad de Bogotá D.C.}

Este literal se ocupa de dos aspectos: ubicar al lector en el perímetro rural de la ciudad de Bogotá D. C. y en el tema específico de los acueductos veredales.

\section{El perímetro rural de la ciudad de Bogotá D.C.}

Aquí se cubren dos aspectos de la ruralidad de la ciudad de Bogotá: por una parte su ubicación y características fundamentales (1.1.) y, por otra, las políticas del agua en este perímetro (1.2). En ambos casos se usará como fuente de información la Política Pública Distrital de Ruralidad tanto de $2006^{22}$ como de 2010 y los insumos de información obtenidos de algunas dependencias del propio Distrito.

22 Desde un enfoque de garantía de los derechos humanos, cuya síntesis de discusión y acuerdos del proceso colectivo de construcción se encuentra en un documento de mayo de 2006, fue adoptada mediante el Decreto 327 de 2007. En adelante se hablará de la política de ruralidad 2006. 


\subsection{Ubicación y características} fundamentales de la ruralidad

La conformación rural de la ciudad de Bogotá D. C. es de aproximadamente 122.256.07 de las 160.686.26 hectáreas que suma la totalidad de su territorio. ${ }^{23}$

La población del área rural de Bogotá para 2010, según Planeación Distrital, era de 16.468 personas; sin embargo del estudio adelantado por la EAAB-ESP sobre treinta acueductos veredales se obtiene que en los censados hay más de 23.000 habitantes en las veredas, sin contar que dicho informe no incluye aquellas personas que habitan las áreas rurales de las localidades de Chapinero, Usaquén, Santa Fe, San Cristóbal, Suba y Bosa, los cuales no fueron objeto de estudio, ni tampoco algunas zonas de Sumapaz. ${ }^{24}$ Lo que hace pensar que el dato acerca de la población rural de Bogotá está desactualizado o desestimado y se supone que la cifra supera los 60000 habitantes, así que la situación del abastecimiento de agua para esta población cada vez se vuelve más relevante.

23 Información suministrada por la Secretaría de Planeación Distrital en derecho de petición 1-2010-12323 de abril 26 de 2010 y que se contradice con la publicada en otros documentos oficiales del Distrito. La Política Distrital de Ruralidad 2006 difería de esta información: "163.661 hectáreas, equivale al $76,6 \%$ del total. Bogotá urbana cuenta, entonces, con 38.305 hectáreas que equivalen al $23,4 \%$ del territorio del Distrito Capital" (p. 10). Por su parte, la Política Distrital de Ruralidad 2010 señaló: "La importancia estratégica de la ruralidad de Bogotá depende en gran parte de su extensión, ya que 163.661 ha equivalen al $76.6 \%$ del total del Distrito, en comparación con el área urbana que cuenta con 38.305 ha que equivalen al $23.4 \%$ del territorio del Distrito Capital” (p. 13).

Ver anexo número 3.
Aunque se habla tradicionalmente de corregimientos y veredas ${ }^{25}$ al referirse a las divisiones rurales o a los "asentamientos humanos en suelo rural", el plan de ordenamiento territorial (РОт), Decreto 619 de $2000^{26}$, los Ilama "centros poblados rurales" 27 y "asentamientos menores", ${ }^{28}$ sin embargo en el Catastro Distrital y en los anexos del mismo рот que se presentan al final del presente texto, se sigue con la denominación "veredas", (anexo 1) y se reportan 61 de ellas (anexo 2).

Durante la investigación de fuentes se elevó solicitud a la Secretaría de Gobierno de Bogotá pidiéndole se sirviera informar entre otras: ¿cuántas áreas urbanas específicas o veredas corresponden a la jurisdicción de la ciudad de Bogotá y en qué localidades están ubicadas? y

25 "Corregimiento: División del área rural del municipio, entendida como una agrupación de veredas que puede incluir o no, un núcleo de población (cabecera corregimental), que satisface la demanda de servicios de su comunidad.

Esta subdivisión tiene como fin mejorar la prestación de los servicios y asegurar la participación de la ciudadanía en el manejo de los asuntos públicos de carácter local.

Los corregimientos pueden corresponder a grupos de veredas o a un centro poblado, teniendo en cuenta que no todas las veredas tienen que estar necesariamente agrupadas en corregimientos, ya que se pueden servir, por ejemplo de la cabecera municipal.

Vereda: Subdivisión del área rural de un municipio, que puede tener límites naturales, geográficos o artificiales. Esta subdivisión se asocia a elementos de identidad socio-cultural y está relacionada con agrupación de predios (fincas)". (http://planeacion.gobant.gov.co/noticias/prensa16.html).

26 Para la elaboración de este estudio se tuvo en cuenta el Pot del año 2000, el cual ante la disyuntiva de suspensión del Decreto 364 de 2013 se ha considerado vigente con ultractividad.

27 "Asentamientos rurales nucleados, con vivienda concentrada, que albergan servicios públicos, sociales, asistenciales, administrativos, recreativos y culturales, y que atienden la población dispersa de las veredas en su área de influencia" (art. 391 POT)

28 "Poblado rural con vivienda dispersa, que concentra algunos servicios para la población circundante" (art. 395 РОт). 
¿cuáles son las localidades del Distrito en donde existe el mayor número de comunidades organizadas prestadoras del servicio público de acueducto y alcantarillado? (entiéndase, organizaciones sociales sin ánimo de lucro, juntas de acción comunal, organizaciones comunitarias o juntas veredales que prestan este servicio). La mencionada Entidad nada dijo sobre el particular; alguna respuesta parcial la obtuvimos de la EAAB, empresa que da cuenta de las veredas que están relacionadas con algún acueducto veredal. Así, el dato que se obtuvo de las veredas es inferido del censo de los acueductos y su comparación con los anexos del POT.

Entonces, se obtuvo información de 33 acueductos veredales, ${ }^{29}$ esto es, aquellos en los cuales la EAAB-ESP ha tenido alguna injerencia a través de su uEL, bien sea construyéndolos o interviniéndolos técnicamente. Estos 33 acueductos veredales operan el servicio aproximadamente para 40 veredas de la ciudad. En conclusión, el Distrito Capital o se abstuvo de suministrar o no posee información sobre la situación de prestación del servicio de acueducto en las demás veredas que conforman su territorio.

Por lo tanto, las referencias que se hagan a los acueductos veredales se limitarán al inventario proveído por la EAAB-ESP que se acaba de presentar y que está enlistado en el anexo 3 de este escrito.

29 Acueducto veredal se le denomina a la infraestructura de acueducto construida por el Distrito que se pone a cargo de la comunidad organizada para la prestación del servicio público domiciliario. Ver anexo 3.
Acerca de las características de la zona rural de la ciudad, la Política Pública Distrital de Ruralidad 2006 (en adelante Política 2006) la ha descrito así:

El territorio rural de Bogotá, sobre el lomo de la cordillera oriental, está inserto en un sistema montañoso, que se inicia en la parte sur del Páramo de Sumapaz, en Colombia Huila, y se conecta con el Parque Nacional Natural del Páramo de Chingaza, hacia el nororiente. De allí parten las aguas que abastecen a las poblaciones del piedemonte cordillerano del departamento del Meta, municipios del Norte del Huila, el oriente del Tolima, sur de Cundinamarca y de la parte Norte de la Sabana Cundiboyacense. Este territorio es un corredor biológico e hídrico, que abastece a 13 millones de colombianos.

La Estructura ecológica principal de la Sabana ha sido reconocida por muchos estudios como pieza integrada a esta estructura ecológica regional que, como lo planteó el IDEA de la Universidad Nacional a la Mesa de Planificación Regional Bogotá-Cundinamarca, establece un "sistema de interconexión de estos ecosistemas", que incluye áreas protegidas, zonas de reserva, parques, restos de vegetación natural y el sistema hidrográfico.

Tiene dos parques naturales: Chingaza al nororiente y Sumapaz al sur, 14 reservas forestales, 4 distritos de manejo integrado y un territorio fáunico, a lo cual se agrega el sistema de áreas protegidas del Distrito Capital reconocidas en el Plan de Ordenamiento Territorial, conformado por los corredores ecológicos, el área de manejo especial del río Bogotá (ronda hidráulica y la zona de manejo y preservación), los parques 
urbanos (metropolitanos y zonales) y el Sistema de Áreas Protegidas (4 nacionales o regionales y 67 distritales) (Alcaldía Mayor de Bogotá, 2006, p. 14).

De esta descripción se deduciría que la capital colombiana cuenta con suficientes fuentes hídricas para satisfacer las necesidades de la población rural; no obstante, la idea que se defiende es llevar calidad de agua al campo de manera continua e ininterrumpida, no generar procesos de conurbación. Se reconoce como inapropiado que la zona rural pierda su condición.

\subsection{Política del agua en la zona rural}

En mayo de 2006 el gobierno del entonces alcalde Luis Eduardo Garzón emitió la Política $2006^{30}$ que básicamente recogió el plan de desarrollo para el sector rural de la ciudad por los siguientes años. ${ }^{31}$

En enero 28 de 2010, a través del Decreto 042, la administración Distrital adoptó el Plan de Gestión para el Desarrollo Rural Sostenible

30 "La Política Pública de Ruralidad es una herramienta de gestión del Distrito Capital para el desarrollo y el ordenamiento ambiental sostenibles de su territorio y la superación de la exclusión de su población, en procura de una articulación armoniosa de las diversas dinámicas de una ciudad metropolitana y capital del país y una zona rural dotada de un gran patrimonio ambiental y ecológico de suma importancia para la ciudad, el conjunto de la región y el país" (Alcaldía Mayor de Bogotá, 2006, p. 10)

31 "Para el gobierno distrital la garantía de los derechos no es una simple opción política, sino ante todo una obligación jurídica, derivada del derecho internacional de los derechos humanos y de la Constitución Nacional, en el marco del esfuerzo por construir de manera efectiva el Estado Social de Derecho. La construcción participativa de la Política Pública de Ruralidad constituye un aporte fundamental para avanzar en el ejercicio de una ciudadanía activa, entendida como la posibilidad de que los ciudadanos y ciudadanas rurales ejerzan sus derechos y encuentren en la organización la posibilidad de actuar de forma colectiva y de construir lo público" (Alcaldía Mayor de Bogotá, 2006, p. 10).
(PGDR) 2010 -el cual está reflejado en el documento técnico de soporte del PGDR y hace parte integral del Decreto 042-, con similares objetivos a los de Política 2006. El principal de ellos es "garantizar el desarrollo humano sostenible de las comunidades rurales y la protección del patrimonio ambiental del Distrito Capital, a través de una adecuada articulación entre los ciudadanos, la sociedad civil y las entidades del Distrito Capital" (documento técnico de soporte PGDR, 2010, p. 15).

La política de ruralidad es un documento que recoge, entre otros objetivos específicos, los de inclusión de la periferia rural de la ciudad, el desarrollo humano sostenible y la protección el patrimonio ecológico y ambiental (documento técnico de soporte PGDR, 2010, pp. 15-16).

En ese discurso de protección de "la necesidad de defender la garantía de los derechos" (Alcaldía Mayor de Bogotá, 2006, p. 23) se habló en 2006 del recurso hídrico en los siguientes términos: "El agua no puede ser tratada como un recurso de mercado, sino como un bien público natural, con valor de uso, en armonía con las políticas de ordenamiento territorial, como se consagra en la Constitución Política Nacional. El acceso al agua constituye un derecho humano fundamental que es indispensable defender de la privatización" (Alcaldía Mayor de Bogotá, 2006, p. 23). [Cursivas añadidas].

La política trascrita, que estuvo vigente hasta enero de 2010, propendía por la protección de la privatización del recurso hídrico; sin embargo no es clara la intención de ella, porque se 
cumple en cuanto al carácter público del recurso hídrico, pero como se ha visto, no se cumple frente a las asociaciones comunitarias, ya que son un mecanismo de privatización de la operación autorizado por la Constitución y la Ley 142 de 1994.

No obstante lo anterior, la política del año 2010 omitió la referencia a la privatización o no del recurso hídrico o de la operación y por el contrario señala:

Por lo tanto el acceso al agua es considerado como un derecho fundamental, lo cual incluye disponer de agua limpia o potable para el consumo doméstico así mismo que el consumo humano sea prioritario frente a otros usos. Deberán potencializarse las formas organizativas y el apoyo técnico en torno a los acueductos comunitarios que hoy operan en la zona rural de Bogotá (documento técnico de soporte PGDR, 2010, p. 14). [Cursivas añadidas].

De esta manera, el Distrito abiertamente acogió una forma de privatización que debe potenciar. ${ }^{32}$

\subsection{Los acueductos veredales en Bogotá}

Se ha dicho que para efectos de este escrito se denomina acueducto veredal a la infraestructura de acueducto construida por el Distrito que se pone a cargo de la comunidad organizada para

32 Potenciación que considera necesaria en virtud del panorama actual que la misma política describe: "Las áreas rurales del Distrito presentan problemas en cuanto a la oferta de prestación de servicios públicos, es el caso que pese a encontrarse en zonas con una alta oferta hídrica, el servicio de acueducto en la zona rural es deficiente, en muchos casos el agua suministrada no tiene ningún tipo de tratamiento previo que garantice su calidad" (documento técnico de soporte PGDR, 2010, p. 30). la prestación del servicio público domiciliario. El presente trabajo se limita al análisis del servicio de acueducto en la zona rural, no de alcantariIlado, asunto que requiere un estudio propio.

Para empezar, recuérdese que el artículo 14.22 de la Ley 142 de 1994 define el servicio público domiciliario de acueducto así: "Llamado también servicio público domiciliario de agua potable. Es la distribución municipal de agua apta para el consumo humano, incluida su conexión y medición. También se aplicará esta Ley a las actividades complementarias tales como captación de agua y su procesamiento, tratamiento, almacenamiento, conducción y transporte." Por lo que aquella agua suministrada por un prestador de servicios que no sea potable "apta para el consumo humano" desnaturaliza el servicio público domiciliario, se vuelve otra cosa.

Como se dijo en la introducción de este texto, Bogotá D. C. debería ser ejemplo de eficiente operación del servicio de agua potable en su territorio no solo a nivel urbano, sino rural, y para ello debería generar una estructura fuerte que en efecto garantice su prestación en ese sector.

En adelante se muestra de forma general el trámite de la construcción y entrega para operación de un acueducto veredal en la ciudad de Bogotá.

El Distrito, a través de las alcaldías locales que poseen zona rural ${ }^{33}$ y de un convenio con la EAAB-

33 "El territorio rural del Distrito en lo administrativo está disperso en 9 localidades: Sumapaz con $62,5 \%$ del total del área rural, Usme con $16,2 \%$, Ciudad Bolívar con $8,0 \%$, Usaquén con 2,3\%, Santa Fe 2,6\%, San Cristóbal $2,6 \%$ y Chapinero el $2,8 \%$ y menos del $3 \%$ entre Suba y Bosa" (documento técnico de soporte PGDR, 2010, p. 17). 
ESP, se encarga de invertir en la construcción de dichas infraestructuras. La EAAB-ESP explica así el mecanismo:

Las inversiones que se realizan en el sector veredal del Distrito se efectúan a través del convenio inter administrativo No. 1000-033-00-98 de fecha 15 de mayo de 1998, celebrado entre la Alcaldía Mayor de Bogotá y la EAAB-ESP, el cual permite desarrollar eficientemente las relaciones entre los Fondos de Desarrollo Locales y un operador técnico, con la capacidad e idoneidad suficiente para desarrollar los planes de inversión en obras de acueducto y saneamiento básico en las diferentes localidades (Oficio 30200-S-2010-157024). ${ }^{34}$

Fruto del convenio interadministrativo es la Unidad Ejecutora Local (UEL) del Acueducto de Bogotá, que básicamente actúa como un mandatario de la administración central y local que le entrega recursos para contratar y construir la obra encomendada que finalmente se le entregará a la comunidad organizada.

¿Pero cómo se define el proyecto veredal a construir? Básicamente se trata de un beneficio comunitario obtenido a través de la administración local, bien por intermedio de los miembros de la Junta Administradora Local, también Ilamados ediles, o por instrucción del alcalde local, quienes priorizan y presentan el proyecto de acueducto veredal para viabilidad y estudio técnico de la UeL.

34 El Decreto Distrital 101 del 11 de marzo de 2010, modificado por el Decreto Distrital 153 de abril 21 de 2010, modificó el esquema de contratación a través de las UEL que tenían asiento en diversas entidades y trasladó la competencia para contratar a las alcaldías locales.
Luego de contar con respaldo técnico se procede a la entrega de recursos de la localidad para que la EAAB-ESP adelante el trámite de contratación de la obra y su respectiva interventoría, para así proceder a cumplir el mandato de la construcción del acueducto. Sobre la parte constructiva prefiero no detenerme y más bien llegar al punto de la entrega.

Finalizada, y a punto de la entrega de la obra, comienzan algunas dificultades sociales y jurídicas. ¿A quién se entrega el acueducto veredal? Todo indica, desde el punto de vista meramente jurídico, que el Distrito en aras del mejoramiento de la calidad de vida y la garantía de la prestación de los servicios públicos de la que habla la Constitución Política, ${ }^{35}$ construye la infraestructura pero tiene la posibilidad de entregarla para su operación a un tercero, que para el caso son las comunidades organizadas. El Distrito ha decidido como política central ${ }^{36}$ no asumir la operación de los acueductos veredales, así que los entrega a terceros, regularmente a las comunidades organizadas. La cuestión es: ¿estas personas están preparadas para tal responsabilidad?

Aparece la comunidad a quien se debe entregar una inversión estatal que en promedio, para cada acueducto veredal, asciende a $600 \mathrm{mi}-$ llones de pesos m/cte. (\$600.000.000). ${ }^{37} \mathrm{En}$ teoría la comunidad debería estar no solo legal,

35 Ver parte I-A del presente escrito: El municipio como mecanismo natural del Estado para la prestación del servicio público domiciliario. Ver Política Pública Distrital de Ruralidad, 2010.

37 Dato suministrado por la UEL. 
sino operativamente preparada para asumir la operación del acueducto veredal, sin embargo como se vio en la primera parte del escrito, eso no es así salvo muy contadas excepciones.

Desde el aspecto legal, como se anotó previamente, apenas dos de las asociaciones censadas por la EAAB-ESP cuentan con registro ante la Superintendencia de Servicios Públicos Domiciliarios y más de diez no tienen concesión de aguas por parte de la CAR. Operativamente no disponen de los recursos, la preparación ni la organización para asumir la administración de tales construcciones. Esto se evidencia en cifras; por ejemplo, en el índice de calidad del agua se muestra que el nivel de coliformes es elevado: hasta 167 en la vereda La Margarita de la localidad de Usme, cuyo acueducto para la fecha del estudio era operado por Acuamar ESP.

Un estudio preparado por la EAAB-ESP por intermedio de un contrato de consultoría, ${ }^{38}$ mostró el análisis de laboratorio de las aguas que ofrecen 30 de los 33 acueductos veredales censados por esa entidad. Llama ampliamente la atención que salvo tres de los acueductos analizados, todos los demás presentaron algún nivel de coliformes, ${ }^{39}$ lo cual es bastante

38 El objeto del contrato en mención es: "Consultoría para realizar el peritaje técnico de redes de distribución de acueductos veredales y peritaje de calidad de abastecimiento de agua para consumo doméstico en las localidades de Sumapaz, Usme, Ciudad Bolívar en Bogotá, D. C."

39 La Resolución 2115 de 22 junio de 2007 emitida por el Ministerio de Protección Social y el Ministerio de Ambiente, Vivienda y Desarrollo Territorial define: "Coliformes: Es un indicador de contaminación microbiológica del agua para consumo humano". También definido por glosario.net (http://ciencia.glosario.net/medio-ambiente-acuatico/coliforme-10276.html) como "microorganismos indicadores de contaminación fecal". grave para cualquier prestador del servicio de acueducto.

Según el Decreto 475 de 1998 (vigente) sobre "normas de calidad del agua potable", también llamada RAS 2000, el "valor máximo admisible" de coliformes es cero $(0)$, de lo contrario pierde potabilidad y no es apta para el consumo humano. ${ }^{40}$

La operación del acueducto veredal supone el mantenimiento de las redes, el tratamiento del agua, el recaudo de la tarifa, el cumplimiento de las obligaciones con los entes de control y vigilancia de los prestadores del servicio, etc., lo que supone la existencia de un grupo ejecutor y unos costos básicos de operación.

Para finalizar la cuestión de la entrega de las obras a las asociaciones comunitarias, baste con agregar que esta no se hace de manera formal, ni siquiera se verifica que la asociación cumpla con mínimos de operación. De ahí se desprenden muchos de los inconvenientes que hoy existen en la operación de los acueductos, como obras en abandono, sin mantenimiento, tratamiento deficiente de las aguas, etc.

\section{B. La experiencia del servicio de acueducto veredal}

Con los datos y las cifras expuestas en el literal anterior, procedí ${ }^{41}$ a realizar trabajo de campo

40 En el anexo 3 de este escrito, la columna "Calidad-Coliformes" registra el nivel de coliformes en los acueductos veredales analizados por la EAAB-ESP.

41 A partir de aquí modifico el discurso a primera persona para mostrar más cercanía con el proceso empírico que describiré. 
en algunos acueductos veredales de la ciudad. Para seleccionarlos me interesaron básicamente dos criterios: el cumplimiento de las normas sobre operación del servicio público señaladas por la SSPD y la calidad del agua según los informes contratados por la EAAB-ESP.

Visité los acueductos veredales de (i) Mochuelo Bajo, con aproximadamente diez años de construcción; (ii) Pasquilla, con aproximadamente dos años de construcción y (iii) la Unión y Andes, con dos años y medio de construcción, los cuales son operados en su orden por la Asociación de Usuarios de Aguas Calientes, Asociación Pasquilla Centro y Asopicos de Bocagrande E.S.P. (La Unión y Andes).

I) La Asociación de Usuarios de Aguas Calientes, que presta su servicio a la vereda Mochuelo Bajo de la localidad de Ciudad Bolívar, es una de las dos asociaciones con autorización para operar por parte de la SSPD, ${ }^{42}$ cuenta con concesión de aguas otorgada por la $\mathrm{CAR}^{43}$ no ha sido sancionada por los organismos de vigilancia y tiene una población usuaria de 3700 personas, la más alta de todos los acueductos veredales reportados por la EAAB-ESP, lo que a primera vista denota su solidez; sin embargo, en materia de calidad de agua reportó un nivel de coliformes de 3. Con estos antecedentes consideré oportuno conocer su funcionamiento.

42 La otra asociación que cumple con estos requisitos es la Asociación de Usuarios Acueducto Aguas Claras, vereda Olarte.

43 La Corporación Autónoma Regional, en Oficio 20102103461 del 3 de marzo de 2010 , da un listado de 24 concesiones de aguas para asociaciones que prestan servicio en la zona rural de la ciudad de Bogotá, D.C.
II) La segunda experiencia que mostraré se trata del acueducto de la vereda Pasquilla, operado por la Asociación Pasquilla Centro, con 2395 usuarios, no está registrada ante la SSPD, tiene concesión de aguas por parte de la CAR y, además, es uno de los tres acueductos veredales que tras la prueba de laboratorio dio un resultado cero (0) en el nivel de coliformes. Según información técnica, es quizá el acueducto con la mejor agua potable del sector rural de Bogotá.

III) El tercer acueducto lleva agua a las veredas La Unión y Andes de la localidad de Usme, y surte a 480 habitantes, es operado por Asopicos de Bocagrande E.s.P., que no está registrada ante la SSPD, no tiene concesión de aguas y el nivel de coliformes fue de 9. Fue entregado a la comunidad hace aproximadamente dos años pero por dificultades técnicas y de administración entró en operación apenas un mes y medio antes de cuando hicimos la visita a terreno. Si bien este no es el peor de los casos que se pueden describir, sí es un ejemplo típico de las dificultades que tiene la comunidad para ponerse al frente de la operación del servicio de acueducto en el sector rural.

En las visitas pude hacer entrevistas a los tres administradores o representantes legales de las asociaciones comunitarias, a una población amplia de usuarios por cada acueducto veredal y a dos de los tres fontaneros ${ }^{44}$ de los acueductos seleccionados. Este ejercicio de investigación

\footnotetext{
44 "Persona especializada en la instalación, mantenimiento y reparación de las conducciones de agua y otros fluidos, así como de otros servicios sanitarios y de calefacción en los edificios" (Diccionario de la lengua española [en línea]. Para el caso de los acueductos veredales que estamos hablando, se denomina así a la persona que hace el tratamiento físico al agua con el fin que sea potable, y que revisa las conducciones.
} 
cualitativa lo presento en un informe que englobé en tres planos: el político, el de administración propiamente dicho, y el de calidad del agua.

Sobre este último aspecto, que parecería el más importante para un observador externo, anticipo que para los usuarios del servicio no es relevante la calidad del agua que consumen, pues consideran que es la misma agua que siempre han utilizado en sus hogares y nunca les ha generado ningún inconveniente de salud; su criterio de valoración está dado por el factor económico, de ahí que al ser interrogados sobre la posibilidad de que la EAAB-ESP asumiera la operación de los acueductos veredales, sin excepción la desecharon por costosa y porque estiman que ellos son dueños de su agua y no tienen por qué ir a otro lugar para obtenerla.

El día que llegué a Mochuelo Bajo, a eso de las ocho de la mañana, y quizá de forma imprudente, pregunté a una de las vecinas del sector si el olor que se sentía en el ambiente era permanente o esporádico. La señora extrañada me dijo: “¿cuál olor?, ahorita mismo no se siente nada, ¿debe ser que es la primera vez que usted viene por acá?", ante su respuesta asentí. El olor a basura en descomposición se debe a que la vereda es vecina del relleno sanitario Doña Juana, ${ }^{45}$ así que permanentemente esta comunidad está en contacto con los malos olores que de allí provienen.

45

Depósito de prácticamente la totalidad de los residuos sólidos de la ciudad de Bogotá, D. C.
La Asociación de Usuarios de Aguas Calientes posee una pequeña casa de su propiedad que hace las veces de sede administrativa y operativa, es allí donde recaudan, atienden a la comunidad y les sirve de central técnica de operaciones.

Mochuelo Bajo es una vereda ubicada justo a la salida de la zona urbana de la localidad de Ciudad Bolívar, básicamente no hay espacio rural entre ellas y tampoco se siente un ambiente distinto al de la ciudad, salvo cuando se visita el nacimiento de las aguas que surten el acueducto veredal, que sí está en el campo. Se percibe un ambiente urbano de personas que viven de la industria ladrillera y de trabajos normalmente en la ciudad.

Pasquilla, igualmente ubicada en la localidad de Ciudad Bolívar, es una zona rural con un pequeño centro urbano rodeado de capilla, colegio y sede del corregidor; está a 25 minutos en vehículo de la zona urbana; al llegar se siente un ambiente de municipio pequeño.

El fontanero, aparte de las labores que le exige el tratamiento del agua del acueducto, también se encarga de la limpieza de la plaza central de la vereda, actividad que estaba realizando cuando lo entrevistamos. Comparado con Mochuelo Bajo, en Pasquilla se siente un ambiente de población de clima frío, rodeada principalmente por cultivos de papa y ganadería de leche; los campesinos se reúnen en la plaza central y fue allí donde pude interactuar con ellos y preguntarles por el estado del acueducto veredal. 
Para llegar a las veredas La Unión y Andes debe irse por Usme, más o menos a 30 minutos en vehículo de la zona urbana. No se observa una plaza central, ni centro urbano; para encontrar algún habitante hay que desplazarse de finca en finca o potrero en potrero, los trayectos y recorridos entre un lugar y otro son grandes. Subir a la planta de tratamiento del acueducto veredal nos tomó más de media hora a pie, ya allí se puede ver el gran valle que conforman las dos veredas. Cuando llegamos a la cima de la montaña donde construyeron la planta de tratamiento nos encontramos con el fontanero, que estaba justamente haciendo tratamiento de las aguas.

Hasta aquí he querido describir las áreas visitadas. En adelante y con el fin de guardar de alguna forma reserva de las identidades de las personas que atendieron mis preguntas, haré un recuento de la situación de estos acueductos, resaltando aquellos aspectos que caracterizan su operación. Para no extender demasiado el recuento o repetir las impresiones, solo tomaré los comentarios recurrentes.

En las entrevistas con los usuarios de los acueductos veredales se observó una tensión que podría denominar "política" respecto a la administración; afirmaciones como “No... pues acá hasta el momento se ha manejado bien sino que usted sabe que en todas partes hay roces entre personas que quisieran tenerlo, uno quisiera tenerlo, el otro, y pues eso, pero de lo demás no, por el servicio no, el servicio ha sido bueno y pues hasta el momento... yo creo que hasta este año cambia porque como que eso es cada dos años que..." o "entonces ya después de que tuvo todo esto ya se encargaron las juntas... ya después de que dijeron sí señor vamos a hacer esto, vamos a hacer esto, si no el error más grande fue que se metió una señora y dijo ah! soy yo... y así fue".

Quizá esta tensión se deba a la manera como se escogen los dignatarios de las asociaciones: por elección popular. Lo que lleva a que el aspecto electoral en estas asociaciones tenga gran interés e influencia.

Esto, con las dificultades que trae el cumplimiento de los requisitos de elección (quórum y mayorías) y la misma selección de los administradores, así lo manifiestaron los propios entrevistados: "La misma comunidad se reúne en una asamblea y nombran la junta y el presidente, el vicepresidente, tesorera y una fiscal, ella [refiriéndose a la presidenta] lleva como cinco años, nunca la cambian" o

hicimos reuniones y yo estaba haciendo parte de otro proceso, pero bueno, me dijeron que le hiciera el favor y que les ayudara y aquí sigo en las elecciones, se suponía que lo que estábamos haciendo era para que nos ayudaran, pero se hicieron las elecciones por cada sector, yo pertenezco al sector rural y por votación el mayor número de votos formaban la junta, con el mayor número de votos se dieron los cargos para la junta directiva,

"se supone que la hacen cada año, hace como ocho días la hicimos pero no hubo quórum decisorio y tenemos unos estatutos que nos obligan a tomar decisiones con un quórum y no lo 
hubo". Sin embargo, detrás de toda esta situación tirante y la dificultad que genera la toma de decisiones, ${ }^{46}$ se resalta el ánimo fiscalizador que tienen los propios habitantes de la comunidad frente a la administración.

La conclusión, a vista de un presidente de asociación:

el problema de los acueductos veredales es la comunidad, la característica de los pobladores es que es muy alborotada, muy reacia a que le pongan a una persona de afuera, entonces ellos piensan que si el agua nace ahí no tienen por qué cobrarles nada, pero ellos no son conscientes de que hay que pagarle a los fontaneros y tampoco ven que ya no tenemos agua cada dos horas con las mangueras sino las 24 horas; ellos no quieren pagar servicios según dicen al Estado, pero ellos no ven que los mismos recursos que llegan a las veredas es para el mejoramiento de la calidad de vida.

Pero esto apenas muestra la dificultad de conformación de las juntas y la elección de los dirigentes de las asociaciones que es el primer paso, pero no el más simple, para asumir la operación del acueducto. Dependiendo de la asociación, estas cuentan con presidencia, tesorería, secretaría, y las más grandes con contador y abogado, algunos con remuneración, otros sin ella. Después viene la toma de posesión del acueducto veredal.

46 La más relevante es la definición de la tarifa: "tenemos que reunir a la población para poner una tarifa, nosotros hemos tratado de seguir pero no se ha podido porque se necesita a la asamblea, una cantidad de gente para aprobar la tarifa, firmar entre 700 usuarios es difícil" (presidente de asociación).
Ante la inquietud de quién les entregó el acueducto veredal para su operación, las respuestas fueron dicientes:

no, la Alcaldía no ha podido entregar, por lo que hay una falla, que estamos en la legalización de los predios, entonces no se ha entregado y la Alcaldía tampoco lo puede recibir porque no es la encargada de eso, estamos buscando la figura jurídica para que lo entreguen como deben... todo es verbalmente pero no lo entregó... El alcalde en ese tiempo, quién sabe quién sería... entonces nosotros lo estamos manejando porque somos los que tenemos las concesiones de las aguas, tenemos los permisos, somos los que manejamos la cámara y somos los que prestamos el servicio, pero la verdad lo único que hay es un acta de entrega en donde vino el constructor y todo eso pero el documento que hicimos como un comodato de la Alcaldía hacia Aguas Calientes, tampoco está elaborado.

\section{O incluso más severas:}

no, el ingeniero sí firmó [refiriéndose al paz y salvo que debe dar la comunidad para efectos de permitir la liquidación del contrato de obra], ${ }^{47}$ le hizo firmar al representante legal la entrega de un acueducto formal totalmente en óptimas condiciones de todo... de todo... y lo firmó el representante, por ser una persona campesina y no mirar lo que estaba firmando, entonces ahí es donde le digo que llega el cam-

47 Así lo aclara en la siguiente pregunta relacionada con la formación de la Asociación: "estaba constituida pero resulta y pasa que le hicieron firmar, porque allá no le dijeron: el acueducto está totalmente allá... no, le dijeron mire, en engaños y en cosas, le hicieron firmar la acta para la liquidación del contrato pero allá nunca nos habían entregado nada... verdaderamente es que yo creo que ni la acta se la hicieron firmar allá en donde fue el acueducto, sino creo que fue por aquí en Usme o en Bogotá... entonces son cosas que son ingenieros que tienen una visión como apenas de ir y explotar y hacer lo que ellos querían". 
pesino, el representante de eso y lo estrellan, porque usted dice: no, es que yo voy a marchar aquí a las mil maravillas y resulta y pasa que no, porque los acueductos están mal diseñados, mal construidos y no le va a poder prestar un servicio a una comunidad ni le va a poder cumplir.

Y la realidad es que la inversión realizada por las alcaldías locales se entrega informalmente a las asociaciones, sin preparación ni capacitación previa. En cuanto a la formación de los administradores de la asociación, tenemos que uno de ellos tiene estudios de educación técnica, los otros dos tienen educación básica.

Sobre la administración de la asociación y del acueducto veredal, en las visitas se observaron grandes limitaciones en infraestructura y capacitación; así lo reconocen los propios representantes de las asociaciones. Como se dijo en la primera parte de este escrito, las asociaciones organizadas tienen las mismas cargas de las empresas de servicios públicos domiciliarios privadas o estatales, sin importar su tamaño o número de usuarios, y de eso son conscientes los propios administradores, el inconveniente es cómo cumplir esas leyes, por lo que prefieren seguir en la informalidad a someterse a todas las cargas.

Cuando confronté a un representante sobre la razón por la cual no había inscrito su asociación ante la Superintendencia de Servicios Públicos Domiciliarios la respuesta fue:

Ese decreto salió como en el 2005 y fue aprobado en el 2007, y que a partir del 2008 tenía- mos que registrar en la Superintendencia, pero entonces el 2008 de la Alcaldía me pidieron un informe general de control y de vigilancia y me pasaron los papeles allá en la Superintendencia. Allá nos dijeron que teníamos que ingresar al suip (Sistema Único de Información), pero entonces lo que pasa es que allá nadie le para bolas a uno, nadie le explica nada, nada, como les dije un día, es la única entidad que no lo dejan dentrar a uno, ni nadie le da información personalmente, únicamente que por teléfono, que ingrese al sulp, que tiene que ser todo por Internet, pero uno que no sabe manejar un computador ¿qué va a hacer? ... Uno va allá y no puede hablar sino con el celador... pero hay mucha información que uno no la conoce.

Incluso va más allá y me cuenta que funcionarios de la Superintendencia se comunicaron con ellos a través de la Alcaldía Local y les advirtieron de la existencia de una multa en el evento del registro, "nos dijeron que teníamos que acercarnos, que nos llamaban para que fuéramos a rendir informe la segunda semana de abril, pero no ha pasado nada... desde que uno no cumpla con los requisitos no pueden hacer nada".

Pero no solo los permisos, registros y demás actuaciones administrativas son dispendiosos, también lo es la operación. Desde la misma instalación del servicio - por ejemplo, hay usuarios que no aceptan la acometida en su casa, sino en los potreros-, o la dificultad en el cobro de la tarifa; algún administrador se quejaba de la cartera sin cobrar que tenía la asociación.

Sobre las cargas de administrar un acueducto veredal así se pronunció un vecino entrevistado, que justamente hacía parte de la asociación 
cuando entró en funcionamiento el acueducto veredal:

la gente al mirar ese problema que se les venía sobre los hombros, que administrar un acueducto rural no era fácil y más cuando no había la calidad para prestar el servicio, entonces la gente se fue retirando y nadie quiso tomar esa responsabilidad, entonces ahorita por ley, por no perder una personería, pues toca nombrar a cualquier persona, pues cualquier persona puede decir amablemente me comprometo, pero de pronto no ha tenido la experiencia de una administración, no está capacitado y puede tener problemas... en alguna parte habíamos hablado de hacer algunos convenios con el mismo Sena y todo eso para que se capacitaran a los representantes legales, porque yo sé que hay las capacitaciones y se puede... entonces a nivel de acueductos o a nivel de los recursos locales hay para que los capaciten y les hagan ver verdaderamente como son las cosas.

Respecto a las estrictas reglas sobre calidad del agua, un presidente se quejaba:

si antes era buena la calidad del agua y lo que decían los estudios de la cAR, de la misma fuente del agua... los malos comentarios dicen que el agua no es apta para el consumo humano, ahora hay una ley que dice que el agua es para uso doméstico, pero usted sabe que el uso doméstico es para muchas cosas, puede ser para lavar la ropa y hay mucha gente que lo interpreta como solo para consumir, lógico que puede pagar unos tratamientos que es lo que nosotros hacemos en la planta, echarle el cloro y toda esa cuestión para que sea apta para consumo humano.
Uno de los administradores pronunció una sentencia que parece resumir el problema administrativo: “El Acueducto de Bogotá ha tratado de capacitar los operadores, pero uno sufre pensando que van a poner a otro personal y nosotros no necesitamos más personal, hay una cosa que nos pasa a nosotros, tenemos exceso de trabajo porque una sola persona tiene que encargarse de la parte operativa y de la parte administrativa".

En materia de operación y servicio se hizo énfasis en preguntar sobre la tarifa, la cobertura y su continuidad, obteniendo los siguientes resultados:

En cuanto a la tarifa que se cobra por el suministro, esta depende de la cantidad de agua consumida, cuantificable teniendo en cuenta que hay medidores instalados; se habla de una tarifa para los acueductos visitados de entre cinco y diez mil pesos (\$5.000 - \$10.000) mensuales. Para una familia en promedio de cinco miembros, el cargo fijo, en promedio, es de dos mil pesos $(\$ 2.000)$.

La cobertura es parcial en dos de los tres acueductos veredales. Por ejemplo, en uno de ellos apenas la mitad de la población se beneficia, debido a que el presupuesto no fue suficiente para extender más las redes. Están a la espera de una nueva intervención del Distrito.

Sobre la continuidad del servicio, se observó que el sistema es sensible a factores internos y externos que afectan el suministro permanente, como lo manifiestan los fontaneros. En cuanto 
a factores internos se tienen reacciones como: "hasta ahora llevo una semana que la llevo [el agua] permanentemente, antes sí, pues, habían interrupciones porque el tanque se apocó el agua allá de la bocatoma, entonces pues el tanque duraba dos días para llenarse" o "el acueducto después de que se entregó echó a funcionar como a los... quince meses, está funcionando por ahí ahorita desde noviembre, entonces imagínese lleva noviembre, diciembre, enero, febrero, marzo, lleva cinco meses... en medio uso".

Y las razones del medio uso, como lo afirmó en una respuesta siguiente, es por problemas de construcción,

porque está mal, le hace falta cajas de... le falta no sé qué más cosas que desgraciadamente no quiso poner el ingeniero, cuando él fue y lo construyó, entonces hay mucha presión de agua, por ejemplo hay una parte donde el estanque con su cimiento está más bajito que a donde está la cota del agua, entonces tiene que demorarse dos o tres días para que coja la misma agua, la vaya empacando... entonces todas esas fallas son fallas técnicas.

$Y$ factores externos al propio sistema veredal como: "sí, por falta de lluvia quitábamos el agua a las seis de la tarde y por ahí a las cuatro y media, cinco de la mañana la estábamos poniendo, se hizo el razonamiento hasta la semana pasada y... hasta el martes de la semana pasada, y como esto ya ahora si llovió, bueno, ahora sí no se está suspendiendo, ahora sí ya..." o "pues hasta un cierto punto llega en excelente calidad el agua, pero por ejemplo la problemática que tengo, cuando llueve mucho en las pocas cámaras de quiebre que hay toda esa agua lluvia cae entre la cámara y me daña el tratamiento.

Como se adelantó, un aspecto que creíamos inicialmente era de gran preocupación para los usuarios de los acueductos veredales era el de calidad del agua, sin embargo nos llevamos una sorpresa cuando en realidad no estuvieron muy interesados en conocer el producto que les suministran. Todo indica que los informes que hacen periódicamente algunos representantes de la administración distrital como hospitales públicos y la misma EAAB-ESP no son divulgados entre los usuarios de la comunidad, lo que en principio explicaría la ausencia de interés en este aspecto, sin embargo así vean residuos en el agua, su interés no aumenta, lo que no se explicaría fácilmente, salvo que se acepte que como esa agua nunca les ha hecho daño, tampoco les hará hacia el futuro.

Ante la inquietud sobre la calidad del agua o las enfermedades que pudieran tener por su consumo, se dijo en general: "de ninguna manera aquí ni cuando la tomábamos en manguera que no tenía ningún tratamiento... ahorita por lo menos le aplican hipoclorito".

Sin embargo, los resultados obtenidos por la EAAB-ESP sobre la calidad del agua en los acueductos veredales muestran otra situación y son desconocidos por la comunidad.

Lo que sí generó unánime y gran reacción fue la posibilidad de que el Acueducto de Bogotá asumiera la prestación del servicio en la zona rural: 
no, pues sinceramente en lo que yo como veedora... mmm... y sinceramente en todo lo que yo he visto que hemos andado esta es el agua más pura y limpia que estamos tomando ... lo que sucede es que aquí hay gente que... o habemos gente a veces que de pagar poquito a pagar harto porque eso es lo primero, aquí hay veces que la gente, la gente se queja cuando le suben cien pesos ante todo pues ponen el grito en el cielo, ahora cómo será cuando el acueducto de Bogotá venga, que el metraje es más caro, ahí es donde está la consecuencia ... no, sino que aquí han venido personas que a veces dicen que... quieren entregarle el acueducto a Bogotá y eso es lo que la gente alega acá, que no, que no quieren por ese sistema que le digo porque ya entraría el Acueducto de Bogotá a manejar esto y ya sería todo más caro, y como le estaba diciendo al principio, la gente llora por 200 que le suban y cómo será por un metraje más caro... no, yo creo que con el acueducto de Bogotá puede ser un mejor servicio, más caro, entonces eso es lo que la gente no quiere, ¿si me entiende?

y así, insistentemente con el rechazo a esa propuesta se recibieron reacciones similares de otros pobladores de los sectores recorridos.

\section{CONCLUSIONES}

Quiero precisar que la intención de este escrito no es deslegitimar, ni desfigurar el área rural de Bogotá, tampoco se propende porque esa zona sea invadida por la ciudad o lo urbano, más bien la idea es promocionar no solo su existencia sino la importancia y fortuna que significa para el Distrito contar con una periferia rural plena de recursos naturales. Además, se pretende abo- gar porque esta sea sólida, definida y que posea los servicios necesarios para garantizar una mejor calidad de vida a sus pobladores. Bogotá debería ser ejemplo de fomento y desarrollo rural. Por esta razón una estructura administrativa distrital que supla ciertas necesidades de la prestación del servicio de acueducto en la zona rural sería de gran ayuda para las asociaciones comunitarias.

No se trata de hacer un juicio de valor o jurídico a la forma como las asociaciones realizan su actividad de administración de los acueductos veredales, por el contrario, considero necesario resaltar que con su poco conocimiento y estructura administrativa y técnica llevan a cabo una labor ingrata; más bien se debería dirigir la mirada hacia aquellos que teniendo la infraestructura, el conocimiento y los recursos no hacen presencia en la zona rural, más aún si se sabe que constitucional y legalmente tienen el deber de garantizar y velar por la prestación del servicio público domiciliario en su zona de competencia.

Es evidente que imponer las mismas "cargas" legales de una empresa de servicios públicos domiciliarios a las asociaciones comunitarias, habida consideración de su tamaño y objeto, no es del todo afortunado, quizá esa circunstancia ha generado que la actividad de prestación del servicio de acueducto en la zona rural sea informal.

Posiblemente el argumento económico de la Corte Constitucional de que las empresas de servicios públicos domiciliarios deben buscar el lucro y no son entidades de beneficencia para prestar el servicio en la zona rural ha sido apro- 
piado por la administración distrital, sin embargo no se entiende por qué si asume dicha posición abandona a su suerte grandes inversiones -acueductos veredales-, sin que medie capacitación, verificación de requisitos legales de constitución, registros, etc., ni asuma su entrega formal y deje en manos inexpertas obras civiles de su propiedad. Más bien debería buscar alternativas para que las asociaciones vayan de la mano con el Distrito y cumplan todos los requisitos de carácter técnico y administrativo, sin que ello suponga un mayor costo para el usuario final y reciba un recurso de calidad: agua potable.

No es desalentar el mecanismo de administración a través de las asociaciones, es sumarlo al deber de garantía constitucional por parte del Distrito Capital.

\section{Referencias}

Organización Mundial de la Salud. (s.f.). Agua, saneamiento y salud. Celebración del Decenio Internacional para la Acción: "El Agua Fuente de Vida" 2005-2015. Obtenido de Organización Mundial de la Salud: http://www.who.int/ water_sanitation_health/2005advocguide/ es/index1.html

Alcaldía Mayor de Bogotá. (Mayo, 2006). Política Pública Distrital de Ruralidad. Obtenido de oab: http://oab.ambientebogota.gov.co/.../ politica_publica_distrital_de_ruralidad.pdf

Alcaldía Mayor de Bogotá. (2010). Política Pública Distrital de Ruralidad. Obtenido de oab: http://oab.ambientebogota.gov.co/.../politica_publica_distrital_de_ruralidad.pdf

Concepto SSPD-OJ-2004-274. [Superintendencia de Servicios Públicos Domiciliarios].

Corte Constitucional de Colombia. Sentencia C-741-2003, expediente D-4405 (M. P.: Manuel José Cepeda Espinosa; agosto 28 de 2003).

Decreto 042 de 2010. [Alcaldía de Bogotá]. Por medio del cual se adopta el Plan de Gestión para el Desarrollo Rural Sostenible. Enero 28 de 2010.

Decreto 619 de 2000. [Alcaldía de Bogotá]. Por el cual se adopta el Plan de Ordenamiento Territorial para Santa Fe de Bogotá, Distrito Capital. Julio 18 de 2000.

Empresa de Acueducto y Alcantarillado de Bogotá E.S.P. (15 de marzo de 2010). Información para el control social 2009. La República, (13a).

Expediente 85001-23-31-000-2004-0002701(AP) de 2006. [Consejo de Estado Sala de lo Contencioso Administrativo, sección primera]. Actor: Fundación para la Defensa de la Gente y del Medio Ambiente (Fundegente). Demandado: municipio de Yopal. (Marzo 30 de 2006).

Ley 142 de 1994. Por la cual se establece el régimen de los servicios públicos domiciliarios. Julio 11 de 1994. Do n. ${ }^{\circ} 41433$. 
Ley 197 de 1992. Por la cual se establece el régimen de los servicios públicos domiciliarios. Gaceta del Congreso, año 1 - n. ${ }^{\circ} 162$ del 17 de noviembre de 1992.

Ley 715 de 2001. Por la cual se dictan normas orgánicas en materia de recursos y competencias de conformidad con los artículos 151, 288, 356 y 357 (Acto Legislativo 01 de 2001) de la Constitución Política y se dictan otras disposiciones para organizar la prestación de los servicios de educación y salud, entre otros. Diciembre 21 de 2001. DO n. ${ }^{\circ} 44654$.

Oficio 30200-S-2010-157024. (Empresa de Acueducto y Alcantarillado de Bogotá ESP). 


\section{ANEXOS}

\section{Anexo 1. Mapa de Bogotá con indicación de las veredas}

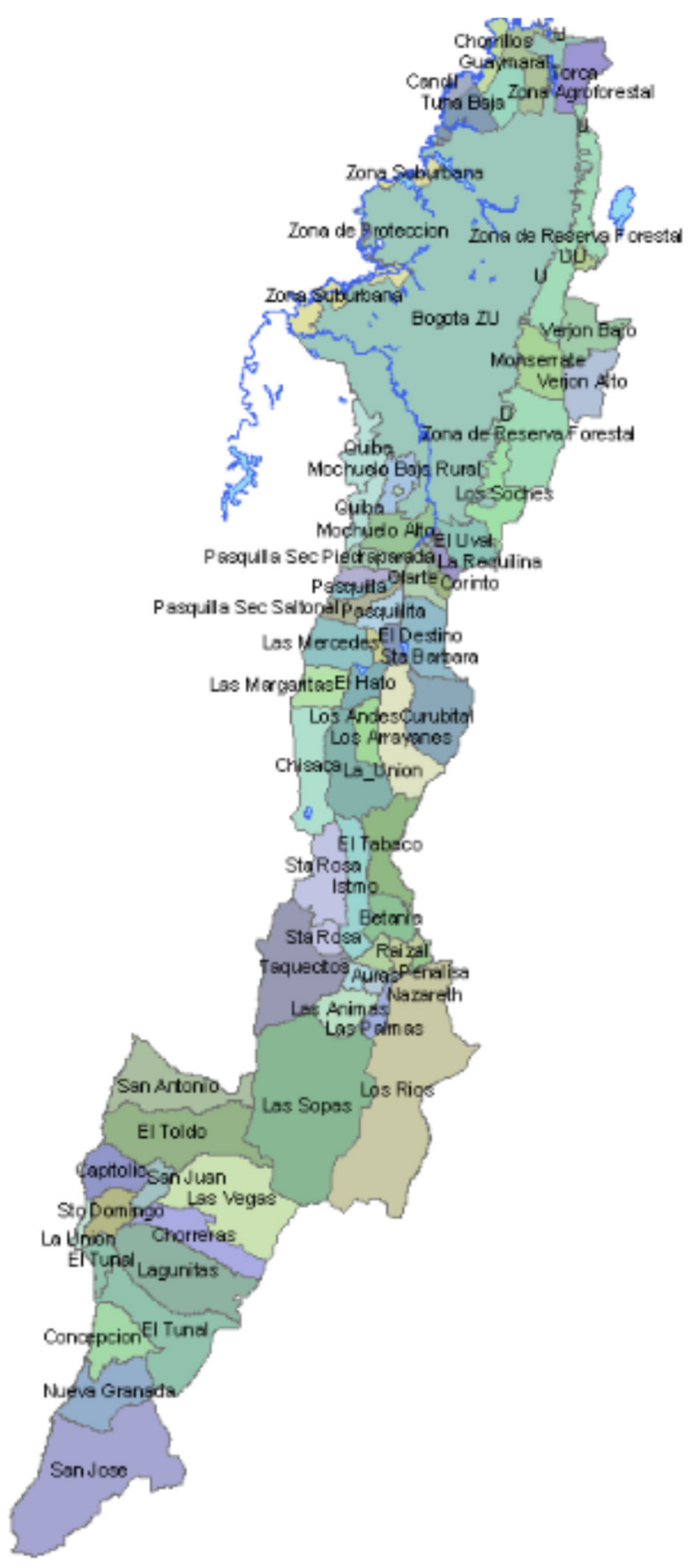

Fuente: Plan de Ordenamiento Territorial de Bogotá, D. C. 
Anexo 2. Las 61 veredas de la ciudad de Bogotá, D. C.

\begin{tabular}{|c|c|c|c|c|c|}
\hline No. & LOCALIDAD & VEREDA & No. & LOCALIDAD & VEREDA \\
\hline 1 & Sumapaz & Auras & 31 & Usme & Los Andes \\
\hline 2 & Sumapaz & Betania & 32 & Usme & Los Arrayanes \\
\hline 3 & Suba & Candil & 33 & Sumapaz & Los Ríos \\
\hline 4 & Sumapaz & Capitolio & 34 & Usme & Los Soches \\
\hline 5 & Usme & Chiguaza & 35 & Ciudad Bolívar & Mochuelo Alto \\
\hline 6 & Sumapaz & Chisacá & 36 & Ciudad Bolívar & Mochuelo Bajo Rural \\
\hline 7 & Sumapaz & Chorreras & 37 & Ciudad Bolívar & Mochuelo Bajo Urbano \\
\hline 8 & Suba & Chorrillos & 38 & Santafé & Monserrate \\
\hline 9 & Sumapaz & Concepción & 39 & Sumapaz & Nazareth \\
\hline 10 & Usme & Corinto & 41 & Sumapaz & Olarte \\
\hline 11 & Usme & Curubital & 42 & Sumapaz & Pasquilla \\
\hline 12 & Usme & El Destino & 43 & Usme & Pasquilla, sec. Cerrito Blanco \\
\hline 13 & Usme & El Hato & 44 & Ciudad Bolívar & Pasquilla, sec. Piedraparada \\
\hline 14 & Sumapaz & El Tabaco & 45 & Ciudad Bolívar & Pasquilla Sec Saltonal \\
\hline 15 & Sumapaz & El Toldo & 46 & Ciudad Bolívar & Pasquillita \\
\hline 16 & Sumapaz & El Tunal & 47 & Ciudad Bolívar & Penalisa \\
\hline 17 & Usme & El Uval & 48 & Ciudad Bolívar & Quiba \\
\hline 18 & Suba & Guaymaral & 49 & Sumapaz & Raizal \\
\hline 19 & Sumapaz & Istmo & 50 & Ciudad Bolívar & San Antonio \\
\hline 20 & Usme & La Requilina & 51 & Sumapaz & San José \\
\hline 21 & Sumapaz & La Unión & 52 & Sumapaz & San Juan \\
\hline 22 & Usme & La Unión & 53 & Sumapaz & Sta. Bárbara \\
\hline 23 & Sumapaz & Laguna Verde & 54 & Sumapaz & Sta. Rosa \\
\hline 24 & Sumapaz & Lagunitas & 55 & Ciudad Bolívar & Sta._Rosa \\
\hline 25 & Sumapaz & Las Ánimas & 56 & Sumapaz & Sto. Domingo \\
\hline 26 & Usme & Las Margaritas & 57 & Ciudad Bolívar & Taquecitos \\
\hline 27 & Ciudad Bolívar & Las Mercedes & 58 & Sumapaz & Torca \\
\hline 28 & Sumapaz & Las Palmas & 59 & Sumapaz & Tuna Baja \\
\hline 29 & Sumapaz & Las Sopas & 60 & Usaquén & Verjón Alto \\
\hline 30 & Sumapaz & Las Vegas & 61 & Suba & Verjón Bajo \\
\hline
\end{tabular}

Fuente: Plan de Ordenamiento Territorial de Bogotá, D. C. 
Anexo 3. Acueductos veredales construidos por la EAAB-ESP a través de la UEL de dicha entidad

\begin{tabular}{|c|c|c|c|c|c|}
\hline Localidad & Acueducto & Vereda & Población & $\begin{array}{l}\text { Calidad - } \\
\text { coliformes }\end{array}$ & Fondos \\
\hline \multirow{9}{*}{$\begin{array}{l}\text { CIUDAD } \\
\text { BOLÍVAR }\end{array}$} & ASOPORQUERA I & $\begin{array}{c}\text { Vereda Mochuelo Alto, } \\
\text { sector El Curubo, El Moral } \\
\text { y Alto de Gallo }\end{array}$ & 750 & 17 & FDL (UEL) \\
\hline & ASOPORQUERA II & Vereda Mochuelo Alto & 250 & 18 & FDL (UEL) \\
\hline & AGUAS CALIENTES & $\begin{array}{c}\text { Mochuelo Bajo sector } \\
\text { veredal, Paticos, La Es- } \\
\text { meralda, Barranquitos, } \\
\text { Lagunitas }\end{array}$ & 3700 & 3 & FDL (UEL) \\
\hline & ACUPASA & Pasquillita, Santa Rosa & 1850 & 4 & FDL (UEL) \\
\hline & ASOQUIBA & $\begin{array}{c}\text { Veredas Quiba Alta, Baja } \\
\text { y Guaval }\end{array}$ & 2200 & 80 & FDL (UEL) \\
\hline & ASOCERRITO BLANCO & Pasquillita, Santa Rosa & 151 & 112 & FDL (UEL) \\
\hline & PASQUILLA CENTRO & Pasquilla Centro & 2395 & 0 & FDL (UEL) \\
\hline & PIEDRA PARADA & $\begin{array}{c}\text { Pasquilla sector Piedra } \\
\text { Parada - Lagunitas Mo- } \\
\text { chuelo Alto }\end{array}$ & 500 & 4 & FDL (UEL) \\
\hline & AACUAVIDA & $\begin{array}{c}\text { Las Mercedes, El Hato, } \\
\text { Santa Bárbara }\end{array}$ & 1120 & 4 & FDL (UEL) \\
\hline \multirow{10}{*}{ USME } & $\begin{array}{l}\text { ASOPICOS DE BOCA- } \\
\text { GRANDE E.S.P. }\end{array}$ & La Unión, Los Andes & 480 & 9 & FDL (UEL) \\
\hline & $\begin{array}{c}\text { A.A. Manantial de } \\
\text { Aguas Cerro Redondo } \\
\text { y Corinto } \\
\end{array}$ & Corinto, Cerro Redondo & 300 & 65 & FDL (UEL) \\
\hline & $\begin{array}{c}\text { Asociación Arrayanes } \\
\text { - Argentina }\end{array}$ & Arrayanes, Argentina & 450 & 9 & FDL (UEL) \\
\hline & $\begin{array}{c}\text { AGUAS CRISTALINAS } \\
\text { (CURUBITAL) }\end{array}$ & Curubital & 350 & 11 & Fonade \\
\hline & $\begin{array}{c}\text { ASOAGUAS DORADAS } \\
\text { E.S.P. }\end{array}$ & Requilina, Uval & 1290 & 27 & Fonade- UEL \\
\hline & ASOAGUA LINDA E.S.P. & Agualinda, Chiguaza & 675 & 0 & Fonade \\
\hline & $\begin{array}{l}\text { AGUAS CRISTALINAS } \\
\text { (LOS SOCHES) }\end{array}$ & Los Soches, Mangueras & 400 & 3 & FDL (UEL) \\
\hline & ACUAMAR & Las Margaritas & 378 & 167 & FDL (UEL) \\
\hline & J.A.A.V. EL DESTINO & El Destino & 1600 & 35 & FDL (UEL) \\
\hline & $\begin{array}{l}\text { Asociación de usuari- } \\
\text { os Aguas claras Olarte }\end{array}$ & Olarte & 816 & 0 & FDL (UEL) \\
\hline
\end{tabular}




\begin{tabular}{|c|c|c|c|c|c|}
\hline \multirow{14}{*}{ SUMAPAZ } & $\begin{array}{l}\text { Acueducto Aguas } \\
\text { Claras }\end{array}$ & $\begin{array}{c}\text { Santo Domingo, La Unión } \\
\text { y Capitolio. }\end{array}$ & 328 & 135 & FDL (UEL) \\
\hline & ASOUAN & $\begin{array}{c}\text { Ánimas Altas, Nazareth, } \\
\text { Las Auras }\end{array}$ & 520 & 24 & FDL (UEL) \\
\hline & Las Vegas Chorreras & Las Vegas Chorreras & 270 & 12 & \\
\hline & Asoperabeca I & $\begin{array}{c}\text { Betania, Peñalisa, Raizal, } \\
\text { Carmen }\end{array}$ & 900 & 1 & FDL (UEL) \\
\hline & Asoperabeca II & El Tabaco, El Itsmo & 270 & 18 & FDL (UEL) \\
\hline & San Juan & San Juan & 200 & 5 & FDL (UEL) \\
\hline & Brisas del Gobernador & Lagunitas, Gobernador & NR & NR & FDL (UEL) \\
\hline & JAC & Los Ríos, Las Palmas & 150 & 69 & FDL (UEL) \\
\hline & $\begin{array}{c}\text { Asoagua y Cañizo } \\
\text { Vereda Ánimas Bajas }\end{array}$ & Ánimas Bajas & 180 & 93 & FDL (UEL) \\
\hline & Tunales & San Antonio, El Toldo & NR & NR & $\begin{array}{l}\text { FDL (UEL)- } \\
\text { Fonade }\end{array}$ \\
\hline & Aso laguna Verde ESP & Laguna Verde & 100 & 135 & FDL (UEL) \\
\hline & Asomedia Naranja & Taquecitos, Santa Rosa & 225 & 3 & FDL (UEL) \\
\hline & Amigos del Páramo & San Antonio, El Toldo & 300 & 1 & FDL (UEL) \\
\hline & Plan de Sumapaz & $\begin{array}{c}\text { Nueva Granada, San José, } \\
\text { Concepción }\end{array}$ & NR & NR & $\begin{array}{l}\text { FDL (UEL)- } \\
\text { Fonade }\end{array}$ \\
\hline
\end{tabular}

Fuente: Empresa de Acueducto y Alcantarillado de Bogotá-ESP. 